\title{
Study on the relationship between Oil Consumption and Economic Growth In Quebec
}

\begin{abstract}
Souhila Cherfi
ABSTRACT

Oil has maintained a dominant part of Quebec's energy balance. It is one of the main inputs for manufacturing sectors and transportation, so Oil is also very important for the Quebec's economic growth. This paper investigates the short and long-run causality issues between oil consumption and economic growth in Quebec, using cointegration, and Granger causality test based on error-correction model, from annual data covering the period of 1983-2013. The overall results reveal that there is unidirectional causality running from economic growth to oil consumption without any feedback effects. Thus, oil conservation policies can be initiated without deteriorating economic side-effects in Quebec.
\end{abstract}

Keywords: Oil Consumption, Economic Growth, Cointegration, error-correction model, Granger causality.

\section{INTRODUCTION}

The oil consuming in Quebec lead to two major concerns: Dependence on imports $(100 \%$ of oil consumed in Quebec is imported) and greenhouse gas emissions from fossil fuels. That growing concerns over the environmental consequences, high and volatile energy prices, and the geopolitical climate surrounding fossil fuel production, requires that oil resources be appropriately managed and used.

In recent decades, energy security and climate change have become key concerns. Given the changes in energy policies in response to these issues, the causal relationships between energy consumption and economic growth has become a compelling area of investigation. From an economic point of view, this relationship lies in two aspects: i) the growing dependence of economic growth on energy, and ii) economic growth promoting energy technology advances and large-scale development and utilization of energy.

Various studies (e.g., Akarca and Long, 1979; 1980; Glasure and Lee, 1998; Masih and Masih, 1996; 1997; 1998) have shown i) that the relationship between energy consumption and economic growth varies depending on the country, and ii) the relationship varies in the same country at different times.

The discrepancy in results from a number of factors. These include: i) the different structures and stages of economic development, ii) the use of different econometric methods, iii) the varying time horizon of the analysis, and iv) the type and number of variables employed (Yu and Choi, 1985; Ferguson et al., 2000; Toman and Jemelkova, 2003; Karanfil, 2009; Payne, 2010).

The overall findings show that there is a strong relationship between energy consumption and economic growth. However, that relation does not necessarily imply a "causal" relationship. 
The presence of unidirectional causality from energy consumption to economic growth (growth hypothesis) signals the economy is energy dependent in which case energy conservation policies may have an adverse impact on economic growth.

By contrast, unidirectional causality from economic growth to energy consumption (conservation hypothesis) suggests that energy conservation policies may have little or no impact on economic growth. It is also possible there is bidirectional causality between energy consumption and economic growth (feedback hypothesis) reflecting the interdependence and possible complementarities associated with energy consumption and economic growth.

Finally, the absence of causality between energy consumption and economic growth (neutrality hypothesis) implies that energy conservation policies will have an insignificant impact on economic growth.

In a summary there have been a number of studies conducted to examine the causal relationship between energy consumption, including oil consumption, and economic growth, But there only a few studies specifically addressing the causal relationship between oil consumption and economic growth. However, there has been no empirical work on the causal relationship between oil consumption and economic growth from Quebec. Thus, the investigation of the causality issue needs to be carried out to make an appropriate oil policy.

The purpose of this article is, therefore, to investigate the causality between oil consumption and economic growth by applying modern rigorous techniques of Granger-causality to the Quebec data, and to obtain policy implications from the results.

A major question concerning this issue is which variable should take precedence over the other. Is oil consumption a stimulus for economic growth, or does economic growth lead to oil consumption?

Evidence on either direction shall have a significant bearing upon policy. If, for example, there is unidirectional causality running from oil consumption to economic growth, reducing oil consumption could lead to a fall in economic growth. On the other hand, if a unidirectional causality runs from economic growth to oil consumption, it could imply that policies for reducing oil consumption may be implemented with little or no adverse effects on economic growth. And last, no causality in either direction would indicate that policies for increasing oil consumption do not affect economic growth.

To this end the article is organized as follows. The next section provides a brief overview of the related literature. The third section outlines the methodology employed in this study. Results are presented in the fourth section. Some concluding remarks and policy implications complete the article.

\section{REVIEW OF THE LITERATURE}

Over the years, much research has been carried out to determine a relationship between economic growth and Energy. Neoclassical growth models usually regard capital, labor and land as the primary factors of production, while energy is regarded as an intermediate input eventually produced by the primary factors of production. Furthermore, neoclassical economists often assume that energy and capital are perfectly substitutable (Solow, 1974). 
Energy is assumed to have a relatively minor role in economic production in the mainstream theory of growth. This has been strongly criticised by proponents of ecological economics, which is grounded in the biophysical theory of the role of energy. The law of thermodynamics implies that a minimum quantity of energy is required to carry out the transformation of matter.

Since all production involves the transformation or movement of matter in some way, energy is therefore necessary for economic production and, as a result, economic growth. Furthermore, econometric studies (e.g., Berndt and Wood, 1979; Apostolakis, 1990; Stern, 1993; Frondel and Schmidt, 2002) have employed various functional forms to estimate elasticities of substitution between energy and capital. These studies have shown that capital and energy are, at best weak, substitutes, and are quite possibly complements.

After the oil crisis in the 1970s there has been a growing literature on the causal relationship between energy consumption and economic growth. These studies have employed a variety of time series econometric techniques.

The direction of causality between energy consumption and economic growth has significant policy implications for countries. The literature concerning the relationship between energy consumption and economic growth has led to the emergence of two opposite views. One point of view suggests that energy use is a limiting factor to economic growth. The other point of view suggests that energy is neutral to growth. This is known in the literature as the neutrality hypothesis" which proposes that the cost of energy is a small proportion of GDP, and so it should not have a significant impact on output growth. It has also been argued that the possible impact of energy use on growth will depend on the structure of the economy and the stage of economic growth of the country concerned. As the economy grows its production structure is likely to shift towards services, which are not energy-intensive activities (Solow, 1978; Cheng, 1995; Asafu-Adjaye, J., 2000).

There are a large number of papers examining the empirical relationships between energy use and economic growth. One on the categories these studies in to four main approaches: One approach in based on a traditional VAR (Sims, 1972) and Granger"s causality testing, which assumed that the data are stationary (Erol and Yu, 1987; Abosedra and Baghestani, 1989). The other two approaches are assuming that the variables are non-stationary and consequently, the cointegration technique is the appropriate tool for investigating these relationships (AsafuAdjaye, J., 2000).

Another approach is, based on the Granger (1988) two stage procedure; in this approach the variable are tested pairs by cointegrating relationships and error correction models to test for Granger causality (Glasure and Lee, 1997). In the third approach multivariate estimators are based (Johansen, 1990), which facilitated estimations of systems of equation where restrictions on cointegrating relations can be tested and information on short-run adjustment are investigated. The multivariate approach also allows for more than two variables in the cointegration relationship (see, e.g. Masih and Masih, 1998; Asafu-Adjaye, 2000). The last and fourth approach utilizing the Panel-based error correction models, which providing more powerful tests compared to the time series approach. In some of the literature the focuses is on the relationship between energy consumption and economic growth. However, when it comes to whether energy consumption in the result or a prerequisite for, economic growth, one cannot find a clear trends in the literature. Depending on the methodology used, and the 
country and time period studied, the direction of causality is ambiguous and controversial (Asafu-Adjaye, J., 2000).

On The world, The oil crises in the 1970s reflect the strong dependence of economies on oil well. The present economic situation is still strongly influenced by supply and demand of oil. Oil has been widely accepted as a vital input to industrial development and economic growth. Reynolds (2000) emphasized that oil is the main energy source of large mobile machinery operation and the main driver of economic growth.

In this paper, we intend to examine the relationship between oil consumption and economic growth in Quebec. Appreciating the causal nexus between oil consumption and economic growth is important in the sense of obtaining smooth economic growth or managing demand for oil through constructing proper policies. Some empirical studies on the causality between oil consumption and economic growth have been conducted in some countries for last decades. The empirical findings on the causal relationship between oil consumption and real gross domestic product (GDP) are different from country to country. We do not have any concrete and consistent results yet.

There are four types of findings in the literature. First, unidirectional causality running from economic growth to oil consumption was discovered by Yang (2000) for Taiwan and Aqeel and Butt (2001) for Pakistan. That is, people are more likely to demand oil as the economy develops. However, the reverse causality does not exist, which means demand-side management of oil could be adopted since the less use of oil does not hold back economic growth.

Second, unidirectional causality running from oil consumption to economic growth was detected in China (Zou and Chau, 2006) and Taiwan (Lee and Chang, 2005). An increase in oil consumption could push economic growth in both cases. Shortage of oil supply infrastructure can hinder economic growth. Administers whose country has these cases should cope with growing demand for oil.

Third, Yoo (2006), Yuan et al. (2008), Usama (2011), and Choi and Yoo (forthcoming) found bidirectional causality in South Korea, China, the Middle East and North African countries, and Brazil, respectively.

Lastly, Fatai et al. (2004) and Wolde-Rufael (2004) revealed no causality between oil consumption and economic growth in New Zealand and in Shanghai of China, respectively.

In Quebec, there has been no empirical work on the causal relationship between oil consumption and economic growth in Quebec. Thus, the investigation of the causality issue needs to be carried out to make an appropriate oil policy wish is an important part of Québec's new energy policy.

\section{Granger-Causality and Stationarity}

\section{METHODOLOGY}

The first attempt at testing for the direction of causality was proposed by Granger (1969). The Granger-causality test is a convenient and very general approach for detecting any presence of a causal relationship between two variables. The test is quite simple and straightforward. A time series $(X)$ is said to Granger-cause another time series $(Y)$ if the prediction error of current $Y$ declines by using past values of $X$ in addition to past values of $Y$. 
The Granger-causality test method is selected to be used in this study over other alternative techniques because of the favorable Monte Carlo evidence reported by Guilkey and Salemi (1982) and Geweke and colleagues (1983), particularly for small samples in empirical works.

In order to conduct the Granger-causality test, a series of variables is required to be stationary. It has been shown that using non-stationary data in causality tests can yield spurious causality results (Granger and Newbold, 1974; Stock and Watson, 1989).

Therefore, following Engle and Granger (1987), the author first tests the unit roots of $X$ and $Y$ to confirm the stationarity of each variable. This is done by using both the augmented DickeyFuller (ADF) (Dickey and Fuller, 1979; Said and Dickey, 1984) and the Phillips-Perron (PP) (Phillips and Perron, 1988) tests. In particular, the PP test is known to be robust for a variety of serial correlations and time-dependent heteroscedasticities.

If any variable is found to be nonstationary, we must take the first-difference and then apply the causality test with differenced data.

\section{Cointegration}

The concept of cointegration can be defined as a systematic co-movement among two or more economic variables over the long run. According to Engle and Granger (1987), if $X$ and $Y$ are both non stationary, one would expect that a linear combination of $X$ and $Y$ would be a random walk. However, the two variables may have the property that a particular combination of $X$ and $Y, Z=X-b Y$, is stationary. Thus, if such a property holds true, then we say that $X$ and $Y$ are cointegrated.

If $X$ and $Y$ each are non stationary and co-integrated, then any standard Granger causal inferences will be invalid, and a more comprehensive test of causality based on an errorcorrection model (ECM) should be adopted (Engle and Granger, 1987).

However, if $X$ and $Y$ are both non stationary, and the linear combination of the series of two variables is non stationary, then the standard Granger-causality test should be adopted (Toda and Phillips, 1993; Yang, 2000b). Therefore, it is necessary to test for the co-integration property of the series of oil consumption and economic growth before performing the Grangercausality test. When both series are integrated of the same order, we can proceed to test for the presence of co-integration.

\section{Error-Correction Model}

In the ECM procedure, $X$ Granger-causes $Y$ if either the estimated coefficients on lagged values of $X$ or the estimated coefficient on the lagged value of the error term from the co-integrated regression is statistically significant. Similarly, $Y$ Granger-causes $X$ if either the estimated coefficients on lagged values of $Y$ or the estimated coefficient on the lagged value of the error term from the co-integrated regression is statistically significant.

This procedure specifically allows for a causal linkage between two or more variables stemming from an equilibrium relationship, thus characterizing the long-run equilibrium alignment that persists beyond the short-run adjustment.

If two variables are non stationary, but they become stationary after the first differencing, and co-integrated, the ECMs for the Granger-causality test can be specified accordingly as follows:

$$
\Delta Y t=\alpha 1+\sum_{i=1}^{L 11} \beta 11 i \Delta Y t-1+\sum_{i=1}^{L 12} \beta 12 i \Delta X t-1+\gamma 1 \varepsilon t-1+u 1 t
$$




$$
\Delta X t=\alpha 2+\sum_{i=1}^{L 21} \beta 21 i \Delta X t-1+\sum_{i=1}^{L 22} \beta 22 i \Delta Y t-1+\gamma 2 \varepsilon t-1+u 2 t
$$

where Xt and Yt represent natural logarithms of oil consumption and real GDP, respectively, $\Delta$ is the difference operator, L's are the numbers of lags, $\beta$ 's are parameters to be estimated, $u t^{\prime}$ 's are the serially uncorrelated error terms, and $\varepsilon t-1$ is the error-correction term (ECT), which is derived from the long-run co-integration relationship, Yt $=\eta 0+\eta 1 \mathrm{Xt}+\varepsilon t$ where $\eta$ 's are parameters to be estimated and $\varepsilon$ is error term.

In each equation, the change in the dependent variable is caused not only by their lags but also by the previous period's disequilibrium in level, $\varepsilon t-1$. Given such a specification, the presence of short-run and long-run causality can be tested. Let us consider Eq. (1), if the estimated coefficients on lagged values of oil consumption ( $\beta 12$ 's) are statistically significant, then the implication is that X Granger-causes $Y$ in the short run. This test can be conducted by a joint F-test. On the other hand, long-run causality can be found by testing the significance of the estimated coefficient of ECT $(\gamma 1)$ by a t-test. Finally, the strong Granger-causality can be exposed through a joint test of the statistical significance of $\beta 12$ 's and $\gamma 1$ by a joint F-test. Similar reasoning is possible for examining whether Y Granger-causes X in Eq. (2).

\section{Data}

\section{DATA AND RESULTS}

In order to look into whether there is a causal relationship between oil consumption and economic growth in Quebec, data covering the period 1983-2013 are used. The data on oil consumption and real GDP were found from Quebec Department of Natural Resources and Statistics Canada Data base. Oil consumption is expressed in terms of tonnes oil equivalent (tep). Real GDP in constant local currency unit (Canadian \$2007) is used as a proxy for economic growth. It's noted that all variables are transformed into natural logarithms in order to reduce heteroskedasticity and obtain the growth rate of the relevant variables by their differenced logarithms (Ozturk and Acaravci, 2010).

The variables used in the models are as follows:

- LOIL: natural logarithmic of oil consumption; and

- LGDP: natural logarithmic of real GDP.

Figure 1: Oil consumption and GNP over the period of 1983-2013.

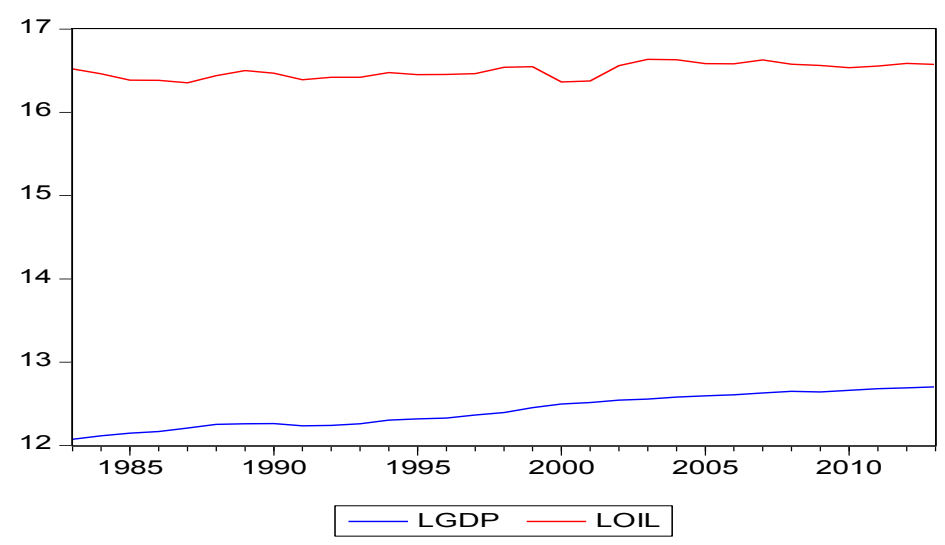

Source: Eviews 6 , from Quebec Department of Natural Resources and Statistics Canada Data base.

The unit root and co-integration tests were used to verify such a relationship. The empirical period was 1983-2013 with all variables measured in natural logarithms. 
To conduct the Granger-causality test, a series of variables are required to be stationary. It has been shown that spurious causality results can occur if non-stationary data is used in causality tests. This paper used the Fisher-type ADF (Augmented Dickey-Fuller) and PP (PhillipsPerron) unit root tests to confirm the stationarity of the series of variables.

\section{Results of unit roots}

Table 1 report the results of the unit root tests (ADF and PP) on the integration properties of the LOIL and LGDP variables. Because the actual values of these series does not exhibit trends and constants, so all unit root test regressions does not include constant and trend terms. The number of lags was equal to 2 for LOIL and 1 for LGDP. The choice of the number of lags employed was assigned to the Akaike Information Criterion (AIC).

The p-values corresponding to the ADF and PP values calculated for the two series are larger than 0.05 . This indicates that the series of all the variables are non-stationary at $5 \%$ level of significance and thus any causal inferences from the two series in levels are invalid.

Table 1: Results of Phillips-Perron (PP) and ADF augmented unit root tests.

\begin{tabular}{cccccc}
\hline Variables & $\begin{array}{c}\text { ADF } \\
\text { Value }\end{array}$ & $\begin{array}{c}\text { Critical } \\
\text { values at 5\% } \\
\text { levels }\end{array}$ & $\begin{array}{c}\text { Lag } \\
\text { Lenght }\end{array}$ & $\begin{array}{c}\text { PP } \\
\text { Value }\end{array}$ & Conclusion \\
\hline On Level & & & & & \\
LOIL & 0.62 & -1.95 & 2 & 0.29 & non stationary variable \\
LGDP & 2.51 & -1.95 & 1 & 5.54 & non stationary variable \\
\hline $\begin{array}{c}\text { On First differences } \\
\text { LOIL }\end{array}$ & -6.38 & -1.95 & 1 & -5.88 & I(1) \\
LGDP & -2.30 & -1.95 & 0 & -2.19 & I(1) \\
\hline
\end{tabular}

Source : Eviews 6.

Note: The optimal lags for the ADF tests were selected based on optimising Akaikes information Criteria AIC, using a range of lags. We use the Eviews soft ware to estimate this value.

The analysis of the first differenced variables shows that the ADF and PP tests statistics for all the variables are less than the critical values at $5 \%$ levels (Table 1). The results show that all the variables are stationary after differencing once, suggesting that all the variables are integrated of order I (1), then the Granger- causality models are estimated with firstdifferenced data.

As indicated, the basic idea behind cointegration is to test whether a linear combination of two individually non-stationary time series is itself stationary. Given that integration of two series is of the same order, it is necessary to test whether the two series are cointegrated over the sample period.

\section{Cointegration Test}

\section{- Method 1: Engle and Granger}

According to Engle and Granger, if both time series are non-stationary, the linear combination of the two time series would be stationary and thus they are co-integrated. Tests of cointegration include the simple two-step test by Engle and Granger (EG) and Johansen's vector auto-regression for more than one co-integrating relationship. The two-step test EG is used in this paper. 
Table 2: First-step: Estimating co-integration equation in the form of:

Dependent Variable: LOIL

Method: Least Squares

Date: 11/16/16 Time: 09:08

Sample: 19832013

Included observations: 31

\begin{tabular}{lrllr}
\hline \hline \multicolumn{1}{c}{ Variable } & Coefficient & Std. Error & t-Statistic & Prob. \\
\hline \multicolumn{1}{c}{ LGDP } & 0.301380 & 0.057723 & 5.221140 & 0.0000 \\
\multicolumn{1}{c}{ C } & 12.75562 & 0.716904 & 17.79265 & 0.0000 \\
\hline \hline R-squared & 0.484539 & Mean dependent var & 16.49823 \\
Adjusted R-squared & 0.466764 & S.D. dependent var & 0.085416 \\
S.E. of regression & 0.062373 & Akaike info criterion & -2.649012 \\
Sum squared resid & 0.112823 & Schwarz criterion & -2.556497 \\
Log likelihood & 43.05969 & Hannan-Quinn criter. & -2.618854 \\
F-statistic & 27.26031 & Durbin-Watson stat & 1.073502 \\
Prob(F-statistic) & 0.000014 & & \\
\hline \hline
\end{tabular}

$$
\text { LOIL }=0.30 * \text { LGDP + } 12.75
$$

\section{-Second-step: test the residus of the Equation}

If $A D F$ test indicates $\varepsilon \sim I(0)$, then is stationary, and Lgdp and Loil are co-integrated. Having OLS estimated the above model of oil consumption and GDP series, ADF-Fisher and PP-Fisher unit root tests for $\varepsilon$ are conducted.

Table 2 indicates the test results on the levels of LGDP and LOIL consumption at the corresponding significant level. The results strongly support the conclusion that a long-run causality relationship between the variables does exist for Quebec.

Table 3: ADF test results on the levels

Null Hypothesis: RESID01 has a unit root

Exogenous: None

Lag Length: 1 (Automatic based on SIC, MAXLAG=7)

\begin{tabular}{lccc}
\hline \hline & t-Statistic & Prob.* \\
\hline \hline Augmented Dickey-Fuller test statistic & -5.564006 & 0.0000 \\
\hline Test critical values: & 1\% level & -2.647120 & \\
& $5 \%$ level & -1.952910 & \\
& 10\% level & -1.610011 & \\
\hline \hline
\end{tabular}

*MacKinnon (1996) one-sided p-values.

The test results indicate that the absolute value of the calculated test statistic for the residual is less than its criticals values. The results show that the residus is stationary. Thus, we can conclude that oil consumption and GNP are cointegrated. That is, there is a long-run relationship between oil consumption and GNP in Quebec.

Therefore, it's hard to have any conclusion about the cointegration between these variables from this simplified test. We then employ the Johansen approach. 


\section{Johansen Test}

\section{Method 2: Johansen Test}

The results of the Johansen cointegration test for the series LOIL and LGDP are reported in

Table 4.

Table 4: Johansen test

Sample (adjusted): 19852013

Included observations: 29 after adjustments

Trend assumption: No deterministic trend (restricted constant)

Series: LOIL LGDP

Lags interval (in first differences): 1 to 1

Unrestricted Cointegration Rank Test (Trace)

\begin{tabular}{ccccc}
\hline \hline $\begin{array}{c}\text { Hypothesized } \\
\text { No. of CE(s) }\end{array}$ & Eigenvalue & $\begin{array}{c}\text { Trace } \\
\text { Statistic }\end{array}$ & $\begin{array}{c}0.05 \\
\text { Critical Value }\end{array}$ & Prob.** $^{* *}$ \\
\hline \hline None ${ }^{*}$ & 0.576497 & 31.24785 & 20.26184 & 0.0010 \\
At most 1 & 0.196130 & 6.331202 & 9.164546 & 0.1667 \\
\hline \hline
\end{tabular}

Trace test indicates 1 cointegrating eqn(s) at the 0.05 level

* denotes rejection of the hypothesis at the 0.05 level

**MacKinnon-Haug-Michelis (1999) p-values

1 Cointegrating Equation(s): $\quad$ Log likelihood 128.4174

Normalized cointegrating coefficients (standard error in parentheses)

LOIL

LGDP

C

1.000000

$-0.328397$

$-12.43621$

(0.04836)

(0.60231)

The likelihood ratio tests show that the null hypothesis of absence of co-integrating relation ( $R$ $=0$ ) can be rejected at the $5 \%$ level, and that the null hypothesis of existence of at most one cointegrating relation $(\mathrm{R}<=1)$ also cannot be rejected at the $10 \%$ level. This implies that oil consumption and real GDP are co-integrated.

LOIL= 0.32 LGDP +12.43

The same result of Eagle and Granger (Method 1).

\section{Results of error-correction model}

If the series of two variables are non-stationary and the linear combination of these two variables is stationary, then the error correction modeling rather than the standard Granger causality test should be employed.

Therefore, an ECM was set up to investigate both short-run and long-run causality. In the ECM, first difference of each endogenous variable (GNP and OIL) was regressed on a period lag of the co integrating equation and lagged first differences of all the endogenous variables in the system, as shown in Eqs. (1) and (2). The results of error correction model are presented in Table 6.

\section{Granger Tests and Causality Results}

Co-integration implies the existence of Granger causality, but it does not point out the direction of the causality relationship. Therefore, the vector error correction model (ECM) is used to detect the direction of the causality. 
Engle and Granger have argued if there was co-integration between the time series, then the vector error correction model can be written as:

Table 5. Granger Causality under tne VECM

VEC Granger Causality/Block Exogeneity Wald Tests

Date: 11/14/16 Time: 10:13

Sample: 19832013

Included observations: 29

\begin{tabular}{cccc}
\hline \hline \multicolumn{2}{l}{ Dependent variable: D(LOIL) } & & \\
\hline \hline Excluded & Chi-sq & df & Prob. \\
\hline \hline D(LGDP) & 4.793877 & 1 & 0.0286 \\
\hline \hline All & 4.793877 & 1 & 0.0286 \\
\hline \hline
\end{tabular}

Dependent variable: D(LGDP)

\begin{tabular}{cccc}
\hline \hline Excluded & Chi-sq & df & Prob. \\
\hline \hline D(LOIL) & 0.764100 & 1 & 0.3820 \\
\hline \hline All & 0.764100 & 1 & 0.3820 \\
\hline \hline
\end{tabular}

Table 6: Results of causality tests based on the error-correction models.

\begin{tabular}{|c|c|c|c|c|c|}
\hline & \multicolumn{5}{|c|}{ Source of causation } \\
\hline & Short & -run & Long-run & run Joint & (long-run) \\
\hline & $\Delta \mathrm{OIL}$ & $\Delta \mathrm{GDP}$ & Et_1 & $\Delta \mathrm{OIL}, \varepsilon \mathrm{\varepsilon t} \_1$ & $\Delta \mathrm{GDP}, \varepsilon \mathrm{\varepsilon t} \_1$ \\
\hline Null hypotheses & F- & values & t-value & F- & values \\
\hline $\begin{array}{l}\text {-Oil consumption does } \\
\text { not cause economic growth }\end{array}$ & $\begin{array}{l}-0.68 \\
(0.31)\end{array}$ & / & $\begin{array}{c}-0.92 \\
(0.15)\end{array}$ & $\begin{array}{c}4.79 \\
(0.38)\end{array}$ & / \\
\hline $\begin{array}{l}\text {-Economic growth does } \\
\text { not cause oil consumption }\end{array}$ & / & $\begin{array}{c}0.05 \\
(\mathbf{0 . 0 5})\end{array}$ & $\begin{array}{c}-0.07 \\
(\mathbf{0 . 0 6})\end{array}$ & / & $\begin{array}{c}0.76 \\
(\mathbf{0 . 0 2})\end{array}$ \\
\hline
\end{tabular}

Notes: The lag lengths are chosen using Akaike's information criterion described in Pantula et al. (1994). The numbers inparentheses below the statistics are p-values calculated under the null hypothesis of no causation. aRejection of the null hypothesis at the $10 \%$ level.

The results of the tests on causality are:

There is no short-run Granger-causality running from oil consumption to economic growth.

The statistical insignificance of the coefficient for the ECT indicates that long-run Grangercausality running from oil consumption to real GDP does not exist.

- Moreover, strong Granger-causality running from oil consumption to economic growth is also absent.

- Overall, there is no causal relationship running from oil consumption to real GDP.

- On the other hand, both the estimated coefficients on lagged values of change in real GDP ( $\triangle \mathrm{GDP}$ ) and the estimated coefficient for the ECT in Eq. (2) are statistically significant at the $10 \%$ level. 
- In addition, the joint hypothesis that both the estimated coefficient for the ECT and the estimated coefficients on lagged values of change in real GDP $(\Delta \mathrm{GDP})$ are zero cannot be rejected at the $10 \%$ level. Thus, short-run, long-run, and strong Granger causality running from real GDP to oil consumption can be found.

- Overall, we can conclude that there is unidirectional causality running from economic growth to oil consumption with no feedback effect.

\section{CONCLUSION}

This paper has investigated the ECM model to examine the causal relationship between oil consumption and GDP in Quebec and to obtain policy implications of the results, using the annual data covering the period of 1983-2013. Prior to testing for causality, the ADF test and Johansen maximum likelihood test were used to examine for unit roots and cointegration.

Empirical results have revealed that there is unidirectional causality running from economic growth to oil consumption without any feedback effect. Thus, a growth in real GDP is responsible for a high level of oil consumption. This study lends support to the argument that an increase in real GDP, gives rise to oil consumption, though there are many other factors affecting oil consumption, and real GDP is only one of such factors. Economic growth results in a higher proportion of real GDP spent on oil consumption, and stimulate further oil consumption. This result can be interpreted as follows.

In this situation, the existence of unidirectional causality running from economic growth to oil consumption in Quebec has important policy implications for decision-makers. Improving oil consumption efficiency of plants, equipments, and vehicles, implementing demand-side management policies such as conservation campaign and regulation of the idling of vehicle engine, and introducing various kinds of tariff reforms aiming to control oil consumption patterns through leveling projected oil products' demand and saving supply costs of oil products, which aim at curtailing the wastage of oil and thereby reducing the oil consumption, can be initiated inducing a high degree of efficiency in the existing facilities with no damaging impact on Quebec economic growth.

The inexistence of the causality from the consumption of oil to economic growth shows that energy consumption does not lead to economic growth and therefore substantial energy consumption is not likely to lead to significant economic growth but an increase in Pollution. It is very important that Québec adopt an appropriate energy policy to promote economic growth while respecting the ecological issue. The efficient use of oil and its substitution by renewable energy could be good policy measures.

\section{References}

Aktaş, Cengiz and Yılmaz, Veysel. (2008) "Causal relationship between oil consumption and economic growth in Turkey”, Kocaeli Üniversitesi Sosyal Bilimler Enstitüsü Dergisi, Vol. 15, pp. 45-55.

Cheng, B. (1995) "An investigation of cointegration and causality between energy consumption and economic growth", Journal of Energy Development, Vol. 21, pp. 73-84.

Dickey, D.A. and Fuller, W.A. (1981) "Likelihood ratio statistics for autoregressive time series with a unit root", Econometrica, Vol. 49, pp. 1057-1072.

Engle, R. F. and Granger, C. W. J. (1987), “Cointegration and error correction: representation, estimation, and testing", Econometrica, 55, 251-276.

Erol, U. and Yu, E.S.H. (1987a) "Time series analysis of the causal relationships between US energy and employment”, Resources Energy, Vol. 9, pp. 75-89. 
Geweke, J., Meese, F., and Dent, W. (1983). “Comparing alternative tests for causality in temporal systems: analytic results and experimental evidence”. Journal of Econometrics, 21, pp 161-194.

Ghosh, S. (2002), "Electricity consumption and economic growth in India”, Energy Policy, 30, pp 125-129

Glasure, Y.U., Lee, A.R. (1997) “Cointegration, error-correction, and the relationship between GDP and energy: the case of South Korea and Singapore”, Resource and Energy Economics, Vol. 20, pp. 17-25.

Granger, C. and Newbold, P. (1974) "Spurious regressions in econometrics”, Journal of Econometrics, Vol. 2, pp. 111-120.

Johansen, S. (1988) "Statistical analysis of cointegrating vectors”, Journal of Economic Dynamics and Control, Vol. 12, pp. 231-254.

Johansen, S. (1991), “Estimation and hypothesis testing of cointegration vectors in Gaussian vector autoregression models", Econometrica, 59, 1551-1580.

Johansen, S. and Juselius, K. (1993), "Testing structural hypotheses in a multivariate cointegration analysis of the PPP and the UIP for UK", Journal of Econometrics, 53, 211244.

Jumbe, C. B.L. (2004), “Cointegration and causality between electricity consumption and GDP: empirical evidence from Malawi”, Energy Economic. 26, 61-68.

Kraft, J. and Kraft, A. (1978) “On the relationship between energy and GDP”, Journal of Energy Development. Vol. 3 , pp. 401-403.

Mackinnon, J. (1991) “Critical values for cointegration tests, long run economic relationships reading, in Cointegration”, Oxford University Press, New York, 267- 76.

Masih, A.M.M., Masih, R. (1998) “A multivariate cointegrated modeling approach in testing temporal causality between energy consumption, real income and prices with an application to two Asian LDCs", Applied Economics, Vol. 30, pp. 1287-1298.

Mehrara, M. (2007). "Energy consumption and economic growth: The case of oil exporting countries", Energy Policy, 35, pp 2939-2945.

Mozumder, P. Marathe, A. (2009). Causality relationship between electricity consumption and GDP in Bangladesh, Energy Policy, 35 (1) pp.395402.

Pesaran, M., Shin, Y. (1999) “An autoregressive distributed lag modeling approach to cointegration analysis” in S. Strom, (ed) Econometrics and Economic Theory in the 20th Century: The Ragnar Frisch centennial Symposium, Cambridge University Press, Cambridge.

Shiu, A.L. and Lam, P.L (2010)." Electricity consumption and economic growth in China”. Energy Policy, 32, pp. 4754.

Usama, A. M. (2011). “Oil consumption, CO2 emission and economic growth in MENA countries”. Energy 36,pp 6165-6172.

Yang, H.Y. (2000). “Coal Consumption and Economic Growth in Taiwan”, Energy Sources, 22, 109-115.

Yang, H.-Y. (2000a), “A note on the causal relationship between energy and GDP in Taiwan”. Energy Economics. 22,pp309-317.

Yoo, S.H. (2006), "Causal relationship between coal consumption and economic growth in Korea”, Applied Energy, 83, 1181-1189

Yu, E.S.H. and Choi, J.Y. (1985), “The causal relationship between energy and GNP: an international comparison”, J. Energy Dev. 10, 249-272.

Zou, G., and Chau, K. W. (2006). "Short- and long-run effects between oil consumption and economic growth in China.on ecomic growth”, American Economist, Vol. 22, pp. 5-11. 